África, África subsahariana, turismo, desarrollo económico

\title{
EL IMPULSO ECONÓMICO MEDIANTE EL TURISMO EN ÁFRICA SUBSAHARIANA
}

\author{
JORGE FERNÁNDEZ RUIZ \\ El Colegio de México
}

El turismo mundial ha crecido aceleradamente desde la década de 1950: ${ }^{1}$ las llegadas de turistas internacionales registradas anualmente se multiplicaron por más de cuarenta entre esa década y el año 2012, para pasar de 25 millones $^{2}$ a más de 1000 millones. Una característica notable de este incremento es que en las últimas décadas ha sido sustancialmente mayor en los países emergentes: mientras que en 1990 captaron $31.9 \%$ de los 436 millones de llegadas de turistas internacionales (139 millones), en 2012 esta cuota de mercado se incrementó a 46.8\% (484 millones de 1035 millones de llegadas internacionales).

En este artículo nos concentramos en África subsahariana. Este subcontinente también ha visto aumentar notablemente - por arriba del promedio mundial - el flujo de turistas que recibe, que se incrementaron de 6.4 millones en 1990 a $33.8 \mathrm{mi}-$ llones en 2012, lo que supone que su cuota de mercado en el turismo mundial se duplicó en ese periodo, para pasar de $1.5 \%$ a $3.3 \%$; fenómeno muy pronunciado en los años más recientes: entre 2005 y 2012 las llegadas de turistas internacionales a África subsahariana crecieron a una tasa media anual de casi el doble (7.1\%) que en el mundo (3.6\%).

Es previsible que en las próximas dos décadas se continúe observando un elevado crecimiento del turismo mundial, con una participación creciente de los países en desarrollo y, en par-

Este artículo fue recibido por la dirección de la revista el 16 de octubre de 2013 y aceptado para su publicación el 15 de noviembre de 2013.

${ }^{1}$ Los datos de esta sección proceden, salvo especificación en contrario, de United Nations World Tourism Organization (UNWTO), Tourism Highlights. 2013 Edition, Madrid, 2013.

${ }^{2}$ Demba Ba y Shaun Mann, Tourism: An Opportunity to Unleash Shared Growth in Africa, Africa Private Sector Development Note 16, Washington, World Bank, 2006. 
ticular, de África subsahariana. En efecto, las proyecciones de la Organización Mundial del Turismo de las Naciones Unidas (UNWTO) ${ }^{3}$ para el periodo $2010-2030$ pronostican un crecimiento promedio de $3.3 \%$ en el turismo mundial y un crecimiento aún más elevado en África subsahariana: de $5.8 \%$ en África oriental; $4.3 \%$ en África austral, y 5.9\% en África occidental y central.

Dos razones que explican la participación creciente de África en el turismo mundial, como argumentan Ba y Mann, son: i) la demanda muestra una mayor preferencia por la diversidad y África ofrece esta diversidad, y ii) hay una mejoría en el acceso desde los mercados europeos, norteamericanos y asiáticos a África gracias a los aeropuertos concentradores (bubs), como Nairobi, Johannesburgo, Addis Abeba y Lagos. ${ }^{4}$

El objetivo del presente trabajo es analizar cómo afecta este crecimiento del turismo la economía en África subsahariana, particularmente de dos países con sectores turísticos importantes: Cabo Verde y Gambia. Para ello, primero analizo, en términos generales, el papel del turismo én el desarrollo económico, con especial atención en el caso de África subsahariana, y posteriormente estudio con más detalle el caso de Gambia, primero, y Cabo Verde, después, para finalizar con unas reflexiones generales.

\section{Consideraciones preliminares sobre el turismo en África subsahariana}

El principal destino turístico en África subsahariana es sin duda Sudáfrica, con más de ocho millones de llegadas de turistas internacionales al año, lo que significa, aproximadamente, la cuarta parte de las llegadas de turistas internacionales - y cerca de la mitad de los ingresos por turismo- ${ }^{5}$ en el subcontinente. Otro grupo de países con elevadas cifras de visitantes y de ingresos

${ }^{3}$ UNwTO, Tourism Highlights, 2013 Edition, op. cit.

${ }^{4}$ Ba y Mann, Tourism: An Opportunity to Unleash Shared Growth in Africa, op. cit. Véase también Christian M. Rogerson, "Reviewing Africa in the Global Tourism Economy”, Development Southern Africa, vol. 24, núm. 3, 2007, pp. 361-379.

${ }^{5}$ Datos para 2011, unwto, Tourism Highlights, 2013 Edition, op. cit. 
por turismo - aunque mucho menores que Sudáfrica-incluye a Kenia, Mauricio y Tanzania. ${ }^{6}$

Sin embargo, como señalan Ashley y Mitchell, debe diferenciarse la importancia que tiene un destino turístico en términos absolutos - usando el número de llegadas de turistas internacionales o alguna otra medida del tamaño del sector turístico-de la importancia que tiene para un determinado país el turismo, es decir, su importancia relativa, que puede medirse, entre otras formas, por la contribución del turismo a las exportaciones o al producto interno bruto (PIB). ${ }^{7}$ Desde este segundo punto de vista, los países de África subsahariana en que tiene más importancia el turismo son Cabo Verde y Gambia. El turismo proporciona $80 \%$ de las exportaciones que realiza Cabo Verde y $79.4 \%$ de las que realiza Gambia; ${ }^{8}$ en contraste, proporciona $10 \%$ en Sudáfrica, $19 \%$ en Kenia, $27 \%$ en Mauricio y $25 \%$ en Tanzania. De manera similar, la contribución total del turismo al PIB (tomando en cuenta no sólo su efecto directo sino también sus derramas sobre otros sectores) es de $44.1 \%$ en Cabo Verde y de $9.8 \%$ en Sudáfrica.

Una observación importante, que destaca Rogerson, es que el crecimiento del turismo en África subsahariana dista mucho de ser uniforme en todo el subcontinente, pues hay muchos países con una afluencia de turistas muy reducida o casi inexistente. $^{9}$

Un factor central para explicar por qué en algunos países no se ha desarrollado el sector turístico es la inestabilidad política y la falta de paz social, fenómeno que puede ilustrarse claramente al contrastar Guinea-Bissau y Cabo Verde, según expongo a continuación.

${ }^{6} \mathrm{El}$ número de llegadas de turistas internacionales, en 2011, fue de 1750000 en Kenia; 965000 en Mauricio, y 843000 en Tanzania, mucho menores que los 8339000 de Sudáfrica. En términos de ingresos por turismo, Mauricio obtuvo 1488 millones de dólares; Tanzania 1353, y Kenia 926. En cambio, la cifra para Sudáfrica fue de 9547 millones. Datos para 2011 (idem.).

${ }^{7}$ Caroline Ashley y Jonathan Mitchell, Can Tourism accelerate Pro-poor Growth in Africa?, Londres, Overseas Development Institute, 2005.

${ }^{8}$ Los datos de la importancia relativa del turismo proporcionados en este párrafo corresponden a 2011 y provienen de World Travel and Tourism Council (wTTC), Travel and Tourism Economic Impact, Londres, 2013.

${ }^{9}$ Rogerson, "Reviewing Africa in the Global Tourism Economy", op. cit. 
Guinea-Bissau y Cabo Verde comparten una herencia colonial similar y obtuvieron su independencia de Portugal, simultáneamente, en 1974-1975, en un proceso liderado por el mismo partido político que operaba en los dos países. Ambos cuentan con atractivos naturales, en particular playas propicias para el turismo, y se encuentran ubicados muy cerca el uno del otro, a una distancia similar de los mercados europeo y norteamericano; sin embargo, mientras que Cabo Verde desarrolló un sector turístico importante, Guinea-Bissau no lo hizo.

La explicación de la diferencia anterior reside en gran medida en que en Guinea-Bissau no ha habido condiciones mínimas de estabilidad política y paz social, necesarias para un crecimiento sostenido del sector. Como afirma Hoffman, la inestabilidad política, los golpes de Estado e incluso las guerras han caracterizado la vida, como país independiente, de Guinea-Bissau. ${ }^{10}$ Entre ellas, un golpe de Estado en 1980, apenas unos años después de su independencia y cuando aún se proponía una integración con Cabo Verde; una guerra civil en 1998-1999 y, más recientemente, en 2009, la muerte en un atentado del jefe de las fuerzas armadas seguido unas horas después por el asesinato del presidente de la república. No es de extrañar que en estas condiciones no pueda desarrollarse el sector turístico; los ingresos por turismo de Guinea-Bissau representan menos de 3\% de los de Cabo Verde. ${ }^{11}$

La inestabilidad política interna que desemboca en violencia puede tener consecuencias importantes incluso en destinos turísticos consolidados, como lo demuestra el caso de Kenia, uno de los destinos turísticos más antiguos en África subsahariana, ${ }^{12}$ en un episodio ocurrido en los años 2007-2008.

${ }^{10}$ Evan Hoffman, "Towards Full Spectrum Conflict Prevention: The International Peace and Prosperity Project in Guinea-Bissau”, Canadian Foreign Policy Journal, vol. 19, núm. 1, 2013, pp. 75-86.

${ }^{11}$ Datos para 2003. Los ingresos turísticos anuales en Cabo Verde eran de 87 millones de dólares, mientras que en Guinea-Bissau, con una población mucho mayor, eran de dos millones de dólares. unwTo, Tourism Market Trend. 2006 Edition, Madrid, 2006.

${ }^{12}$ Véase John S. Akama, “The Evolution of Tourism in Kenya”, Journal of Sustainable Tourism, vol. 7, núm. 1, 1999, pp. 6-25, y John S. Akama, "The Role of Government in the Development of Tourism in Kenya", International Journal of Tourism Research, vol. 4, núm. 1, 2002, pp. 1-13. 
Como documenta De Sausmarez, ${ }^{13}$ en diciembre de 2007 un conflicto electoral que siguió a las elecciones presidenciales desembocó en disturbios violentos que duraron alrededor de dos meses. Pese a que la violencia no se extendió a las principales zonas turísticas y no hubo ningún turista herido, en 2008 hubo una caída de $34 \%$ en las llegadas internacionales comparadas con el año anterior y sólo después de tres años se alcanzaron las cifras previas a la crisis. En el ínterin, los efectos en el sector turístico fueron muy severos. Aunque todo el sector fue afectado, el impacto no fue homogéneo; por ejemplo, los operadores de safaris que atendían los mercados europeo y norteamericano sufrieron, en 2008 , una caída de $80 \%$ respecto de los valores de 2007 y muchas compañías cayeron en bancarrota.

Cabe subrayar que el fuerte deterioro del sector turístico ocurrió a pesar de que el gobierno lanzó una campaña para restaurar la imagen de Kenia, como un destino seguro, desde marzo de 2008. Esta campaña incluyó viajes del Ministerio de Turismo y la Federación de Turismo de Kenia (representando al sector turístico privado) a los principales mercados y ferias de turismo, para transmitir el mensaje de que Kenia era un destino seguro, así como medidas adicionales, entre las que destacan la reducción a la mitad del costo de las visas para entrar a Kenia y el retraso, por dos años, en el aumento previsto en las tarifas de entrada a los parques naturales.

\section{Ventajas y riesgos del turismo como instrumento de desarrollo}

El turismo puede ser un motor importante para el desarrollo económico; de hecho, como señala Rogerson, en el entorno poscolonial africano diversos países lo conceptualizaron como un "pasaporte al desarrollo", ${ }^{14}$ empezando por Egipto, Kenia, Marruecos y Túnez, y extendiéndose después a muchos otros paí-

\footnotetext{
${ }^{13}$ Nicolette De Sausmarez, "Challenges to Kenyan Tourism since 2008: Crisis Management from the Kenyan Tour Operator Perspective”, Current Issues in Tourism, vol. 16, núm. 7-8, 2013, pp. 792-809.

${ }^{14}$ Rogerson, "Reviewing Africa in the Global Tourism Economy", op. cit.
} 
ses del continente que lo incluyeron como un elemento clave en sus planes nacionales de desarrollo.

Una característica central que permite al turismo jugar un papel relevante en el desarrollo económico es que proporciona divisas extranjeras a países con muy pocas opciones para obtenerlas. Según Sinclair, esto explica, en gran medida, su atractivo para los países en desarrollo, pues les hace posible enfrentar problemas de la balanza de pagos, en muchos de ellos frecuentes, así como importar bienes de capital para su desarrollo. Desde hace décadas, en muchos países el turismo es una de las principales fuentes de divisas; por ejemplo, a principios de la década de 1990, en Kenia era ya la principal fuente de divisas habiendo superado al té y al café, y en Gambia ocupaba ya el segundo lugar. ${ }^{15}$

Además de incrementar las exportaciones, el turismo permite diversificarlas, lo que tiene una importancia mayúscula en los países que dependen de la exportación de unas cuantas materias primas.

Pero la importancia económica del turismo puede ir mucho más allá de su papel como proveedor de divisas; esto depende de qué tan fuertes sean sus lazos con el resto de la economía. Aquí existe una enorme variabilidad que, siguiendo a Sinclair, ${ }^{16}$ puede ilustrarse contrastando el caso de España, donde la economía local provee una proporción muy alta de los bienes y servicios que consumen los turistas, con el caso de Fiji, donde incluso el gasto en comida para los turistas tiene un componente muy elevado de importación. ${ }^{17}$ En África subsahariana la situación de Kenia y Gambia, en 1992, ilustra el mismo fenómeno: mientras que Kenia retenía 65\% de las divisas extranjeras que captaba en el sector turístico, Gambia retenía sólo $20 \%$, debido a una base productiva insuficiente. ${ }^{18}$

${ }^{15}$ Thea Sinclair, "Tourism and Economic Development: A Survey", The Journal of Development Studies, vol. 34, núm. 5, 1998, pp. 1-51.

${ }^{16}$ Idem.

${ }^{17}$ Robert C. G. Varley, Tourism in Fiji: Some Economic and Social Problems, Occasional Papers in Economics, núm. 12, Bangor, University of Wales Press, 1978, citado por Sinclair, "Tourism and Economic Development: A Survey", op. cit.

${ }^{18}$ Peter Dieke, Tourism and Structural Adjustment Programmes in the African Economy”, Tourism Economics, vol. 1, núm. 1, 1995, pp. 71-93, citado por Sinclair, "Tourism and Economic Development: A Survey", op. cit. 
El efecto del turismo en la generación de empleo requiere una consideración aparte. Además de que depende también del grado de integración del sector turístico con el resto de la economía, destaco las siguientes dos características: i) genera no sólo empleos de tiempo completo -los más fácilmente identificables-sino muchos de tiempo parcial o temporales, y ii) hay una gran variabilidad entre los países en cuanto al grado en que la población nativa puede ascender y ocupar empleos mejor remunerados, que exigen más habilidades y preparación. ${ }^{19}$

A las ventajas anteriores cabe agregar aquellas señaladas por organizaciones internacionales -como el Banco Mundial, la International Finance Corporation y el Departamento Británico para el Desarrollo Internacional-Overseas Development Institute- que, a principios de este siglo, "redescubrieron" el potencial del turismo como palanca para el desarrollo económico. En esta nueva visión se subrayan ciertas características únicas que hacen al turismo atractivo para promover el desarrollo y aliviar la pobreza, especialmente en lo que se conoce como "turismo pro pobre". Entre estas características sobresalen las siguientes:

i) El hecho de que en la actividad turística sean los consumidores quienes acuden al destino otorga a la población local la oportunidad de vender muchos otros productos y servicios.

ii) El turismo está intrínsecamente basado en el aprovechamiento de los recursos naturales y la cultura locales, donde tiene una ventaja la población pobre de los países en desarrollo que no cuenta con otros recursos.

iii) El turismo permite desarrollar actividades en pequeña escala, que son intensivas en el uso de mano de obra comparadas con otros sectores no agrícolas.

iv) El turismo es especialmente apropiado para proporcionar empleo femenino.

v) Es un sector donde pueden desarrollarse actividades con bajas barreras a la entrada, que no necesariamente requieren de un alto contenido de material importado y que, al con-

${ }^{19}$ Sinclair, “Tourism and Economic Development: A Survey”, op. cit. 
trario, proveen oportunidades para entrelazarse con la economía local. ${ }^{20}$

Los beneficios potenciales del turismo, derivados de las características anteriores, son considerables. ${ }^{21}$ Genera empleos directos tanto de tiempo completo como de tiempo parcial o temporales, así como venta de bienes y servicios que se traducen en empleos indirectos y ganancias para empresas locales e ingresos para empresas comunitarias; genera también impuestos y otras contribuciones que pueden repercutir en inversiones en salud, educación y vivienda; produce una revalorización de algunos activos de la población local y motiva la creación de infraestructura que beneficia a toda la población; produce otros beneficios intangibles, como el aprendizaje de formas de organización y tecnologías más productivas y el establecimiento de relaciones con el exterior que pueden ser útiles en otras áreas; finalmente, induce una revalorización en la política pública de la cultura de las minorías, entre otros beneficios de tipo social.

La otra cara de la moneda es que existe el riesgo de que el turismo se convierta en una actividad provechosa solamente para los países de donde provienen los turistas y las inversiones, pero que ocasione más daños que beneficios a la población local. En efecto, no basta con una mayor afluencia de turistas para que el turismo impulse el desarrollo económico, como ha sido reconocido al menos desde la década de 1980:22 existe el riesgo de que se trate de una actividad desligada de la economía local, dominada por intereses extranjeros, que explote el medio ambiente y la cultura locales y traslade sus ganancias al exterior.

Las siguientes características conforman un ejemplo extremo que ilustra la situación anterior: los turistas extranjeros

${ }^{20}$ Véase Caroline Ashley, Charlotte Boyd y Harold Goodwin, "Pro-poor Tourism: Putting Poverty at the Heart of the Tourism Agenda", Natural Resources Perspectives, núm. 61, 2000, pp. 1-6; Ashley y Mitchell, Can Tourism accelerate Pro-poor Growth in Africa?, op. cit.; Deloitte \& Touche-International Institute for Environment and Development-Overseas Development Institute, Sustainable Tourism and Poverty Elimination Study. A Report to the Department for International Development, Londres, 1999, citado por Ashley, Boyd y Goodwin, "Pro-poor Tourism...”, op. cit.

${ }^{21}$ Véase Ashley, Boyd y Goodwin, "Pro-poor Tourism...”, op. cit.

${ }^{22}$ Véase por ejemplo Ashley y Mitchell, Can Tourism accelerate Pro-poor Growth in Africa?, op. cit., y las referencias allí citadas. 
llegan a su destino en un paquete con todo incluido a una cadena extranjera. El hotel importa los productos que requiere para atender a los turistas, y programa actividades de las que excluye en gran medida a la población local. Como el hotel es propiedad extranjera, transfiere sus ganancias al extranjero. El personal administrativo y gerencial es también extranjero. Más aún -recurriendo a una de las desventajas potenciales del turismo mencionadas por Sinclair- ${ }^{23}$ la presencia de los turistas produce saturación en el uso de los recursos naturales y de la infraestructura pública: se limita el acceso de la población local, en beneficio de los turistas, y se degrada el entorno. ${ }^{24}$

Entonces, las ventajas del turismo son potenciales. Dependiendo de diversos factores, es posible caer en un turismo de "enclave", como el recién descrito, o en algo más cercano a lo preconizado por lo que se ha dado en llamar turismo "pro pobre" ("pro-poor" tourism).

Nada garantiza que una política de laissez-faire evite un turismo de enclave. Ashley, Boyd y Goodwin, ${ }^{25}$ así como Ashley y Mitchell, ${ }^{26}$ en la corriente del turismo pro pobre, señalan que el gobierno dispone de instrumentos que ayudan a evitar este tipo de turismo. Entre ellos destaca un marco regulatorio que dé incentivos para que los hoteles y otras empresas del sector inviertan y operen de forma integrada a la economía local; por ejemplo, el gobierno puede supeditar la autorización de desarrollos turísticos al cumplimiento de condiciones que favorezcan a la población local y eviten su exclusión.

Otros instrumentos son la construcción y mantenimiento de infraestructura adecuada -como el transporte turístico, la generación de energía eléctrica y el drenaje-, la provisión de educación que permita a la población local acceder a los puestos mejor remunerados que requieren mayor capacitación, y la oferta de financiamiento, sobre todo a pequeñas empresas.

Sin embargo, todas las medidas de política pública palidecen en importancia comparadas con una condición esencial para que

\footnotetext{
${ }^{23}$ Sinclair, "Tourism and Economic Development: A Survey", op. cit.

${ }^{24}$ En un caso extremo, el desarrollo del complejo hotelero supone la expulsión de la población local de su lugar de residencia.

${ }^{25}$ Ashley, Boyd y Goodwin, "Pro-poor Tourism...”, op. cit.

${ }^{26}$ Ashley y Mitchell, Can Tourism accelerate Pro-poor Growth in Africa?, op. cit.
} 
el turismo pueda desarrollarse: la existencia de un marco de estabilidad general y paz social que permita a los turistas potenciales disfrutar de todos los demás atractivos que un país pueda ofrecerles. Como afirman Nobelli, Morgan y Nibigira al estudiar las dificultades para promover el turismo en Burundi después de una guerra civil que se prolongó durante doce años, la garantía de la seguridad personal del turista es un requisito para el desarrollo del turismo. ${ }^{27}$ Por eso, al examinar los casos de Gambia y Cabo Verde prestaré especial atención al proceso que condujo a un marco de estabilidad política y paz social y, en algunos casos, a su ruptura.

\section{Gambia}

Para examinar el crecimiento del turismo en Gambia y su relación con el desarrollo económico, presento primero el contexto general en que transcurre este fenómeno, incluidas las condiciones geográficas, y un breve repaso del marco político en sus aspectos relevantes para la actividad turística.

Gambia es uno de los países africanos más pequeños, situado en la costa oeste del continente, casi totalmente rodeado por su vecino, mucho más grande, Senegal: limita con él al este, norte y sur, y al oeste con el Atlántico, en la desembocadura del río Gambia. ${ }^{28}$ El hecho de estar rodeado por un vecino mucho mayor, con una herencia colonial distinta - británica Gambia y francesa Senegal-, ha tenido una fuerte influencia sobre su desarrollo.

Gambia obtuvo su independencia del Reino Unido, en 1965, como resultado de un proceso de negociación, libre de las luchas violentas observadas en otros movimientos de independencia en África. ${ }^{29}$ Fue precedida por varios lustros de participación de

${ }^{27}$ Marina Nobelli, Nigel Morgan y Carmen Nibigira, “Tourism in a Post-Conflict Situation of Fragility”, Annals of Tourism Research, vol. 39, núm. 3, 2012, pp. 14461469.

${ }^{28}$ Este río, que corre de este a oeste, la atraviesa totalmente, y de hecho sus riveras constituyen el territorio de Gambia, que desde su frontera oriental hasta el Atlántico mide unos $350 \mathrm{~km}$ y de sur a norte se extiende a ambos lados del río alcanzando unos $48 \mathrm{~km}$ en su parte más ancha.

${ }^{29} \mathrm{La}$ exposición del desarrollo político de Gambia está basada en Tijan M. 
partidos políticos en procesos democráticos, que el régimen colonial autorizó para evitar la aparición de movimientos nacionalistas que utilizaran la violencia.

En 1959, David Jawara fundó el que posteriormente se convertiría en el Partido Progresista del Pueblo (PPP), ${ }^{30}$ triunfó en las elecciones de 1962 y lideró el proceso de independencia. Fue nombrado primer ministro y condujo al país durante el autogobierno preliminar, que se estableció en 1963, y a partir de la independencia, en un marco de pertenencia a la Commonwealth, desde 1965. El PpP continuó fortaleciéndose en las elecciones de 1966 y 1972 y, en el ínterin, en 1970, promovió y ganó un referéndum que aprobó la transformación de Gambia en una república. Gambia vivió a partir de su independencia un periodo de normalidad democrática que se vio interrumpido por un intento de golpe de Estado, en 1981, y más adelante por un golpe de Estado, en 1994. Como explico más adelante, estos dos episodios tendrían consecuencias importantes sobre el sector turístico.

El intento de golpe de Estado, en julio de 1981, fue liderado por civiles acompañados por fuerzas paramilitares - cabe mencionar que Gambia carecía de ejército en aquel momento- y duró casi una semana, durante la cual las fuerzas rebeldes se hicieron con el control del aeropuerto, el parlamento y la radio. Más de quinientas personas murieron, y la rebelión terminó sofocada por la intervención de fuerzas senegalesas a petición del presidente Jawara, quien invocó un acuerdo de defensa de 1965. El ingrediente principal que creó el caldo de cultivo para la rebelión, como argumenta Sallah, fue el pobre desarrollo económico de Gambia, con una población rural cada vez más

Sallah, "Economics and Politics in The Gambia", The Journal of the Modern African Studies, vol. 28, núm. 4, 1990, pp. 621-648; Abdoulaye Saine, "Post-Coup Politics in Gambia”, Journal of Democracy, vol. 13, núm. 4, 2002, pp. 167-172, y David Perfect, "Politics and Society in The Gambia since Independence", History Compass, vol. 6, núm. 2, 2008, pp. 426-438.

${ }^{30}$ Inicialmente llevaba el nombre de Protectorate People's Party (Partido del Pueblo en el Protectorado) y tenía presencia fundamentalmente en el Protectorado, es decir, en las zonas rurales, en oposición a la Colonia, es decir, la zona urbana, donde operaban otros tres partidos creados entre 1951 y 1952 (Sallah, "Economics and Politics in The Gambia”, op. cit.). 
marginalizada.${ }^{31}$ En efecto, esta situación hizo imposible satisfacer las expectativas creadas por la independencia.

La fragilidad que se puso en evidencia con la rebelión de 1981, y el hecho de que fuera necesaria la intervención senegalesa para sofocarla, precipitaron la formación de una Confederación entre Senegal y Gambia, en febrero de 1982. La idea de una integración de los dos países no era nueva: databa de la época colonial; sin embargo, nunca había fructificado, en gran medida porque aunque Senegal y Gambia compartían muchas características étnicas y culturales, el hecho de haber sido gobernadas por diferentes países europeos se había traducido en legados económicos, lingüísticos y administrativos propios con estrechos vínculos con la metrópoli respectiva. La Confederación estuvo plagada de problemas y se disolvió en 1989, cuando Senegal se retiró de ella después de que Jawara propusiera que la presidencia fuera rotativa entre los dos países.

En 1994 nuevamente se puso de manifiesto la fragilidad política de Gambia, pero esta vez el golpe de Estado no fue solamente tentativo, sino que efectivamente derrocó al gobierno establecido. Pocos años antes, Sallah había señalado que la precaria situación de Gambia había empeorado después de la breve existencia de la Confederación. Apuntaba a los elevados niveles de corrupción, la falta de oportunidades de empleo especialmente entre los jóvenes y el escaso progreso económico acompañado por las elevadas expectativas de la población. ${ }^{32}$

La rebelión de 1994 no fue liderada por civiles, como en 1981, sino por militares, encabezados por el coronel Yahya Jammeh, y esta vez Senegal no intervino para sofocarla. Aunque inicialmente Jammeh había anunciado que los militares permanecerían en el poder cuatro años, atendiendo a protestas internas y a sanciones económicas externas convocó a elecciones en 1996. El resultado fue el triunfo de Jammeh, en un proceso que distintos autores ${ }^{33}$ han cuestionado por el papel de la maquina-

${ }^{31}$ El principal líder de la rebelión, Dominic Sanyang, apeló en su intervención mientras los rebeldes tenían control de la radio, al desempleo e injusticia en el país, y acusó al gobierno de Jawara de corrupción, tribalismo y mal manejo económico (idem.).

${ }^{32}$ Idem.

${ }^{33}$ Saine, "Post-Coup Politics in Gambia", op. cit.; Perfect, "Politics and Society in The Gambia since Independence”, op. cit. 
ria gubernamental y los medios de comunicación. A partir de entonces, Jammeh ha continuado en el poder resultando victorioso en los comicios pero, como argumenta Perfect, sin obtener la legitimidad que el haber liderado el proceso de independencia brindaba a su antecesor y, por otra parte, bajo el cuestionamiento de las condiciones en que se llevan a cabo las elecciones. $^{34}$

En el aspecto económico, antes de su desarrollo turístico Gambia mostraba dos rasgos característicos de los países en desarrollo: la mayoría de su población se dedicaba a la agricultura de subsistencia y sus exportaciones se limitaban a una materia prima y sus derivados: los cacahuates.

Es importante tomar en cuenta el contexto geográfico y climático para entender el desarrollo del sector turístico de Gambia, ubicado en su costa. Gambia se encuentra a seis horas de vuelo y con sólo una hora de diferencia horaria de Londres, lo que la convierte en un destino cómodo para los turistas europeos. Respecto al clima, existen dos temporadas claramente diferenciadas. Tiene un clima lluvioso y con mucho calor de junio a noviembre; pero seco y menos caluroso de noviembre a mayo. Como esta última temporada coincide con el invierno en Europa, las playas de Gambia resultan entonces particularmente atractivas para los turistas europeos. Estas características hacen de Gambia lo que se conoce como un destino de "sol de invierno" ("Winter Sun" destination) y originan una temporada alta de noviembre a mayo y una temporada baja (agujero) de junio a noviembre. Esta estacionalidad es un determinante importante en el funcionamiento del sector turístico y de su influencia en el resto de la economía.

Examinemos ahora el desarrollo del sector turístico. Su nacimiento se remonta a 1967 y está asociado a empresas extranjeras, cuando una empresa sueca construyó el primer hotel que hubo en Gambia, el Wadner Beach Hotel, y el operador turístico sueco Vingressor, asociado con Scandinavian Airlines, obtuvo el monopolio de los vuelos chárter desde y hacia Gambia por cinco años. ${ }^{35}$

${ }^{34} \mathrm{Idem}$.

${ }^{35}$ Sheena Carlisle y Eleri Jones, “The Beach Enclave: A Landscape of Power”, Tourism Management Perspectives, vol. 1, 2012, pp. 9-16. 
El primer esfuerzo planificado de mayores dimensiones para desarrollar el turismo en Gambia, sin embargo, data de la década de $1970 .{ }^{36}$ Haciendo uso de préstamos concesionarios del Banco Mundial ${ }^{37}$ y con la asistencia del Programa de Desarrollo de las Naciones Unidas, ${ }^{38}$ se emprendió el Proyecto de Infraestructura y Turismo entre 1975 y 1980. Este proyecto, conocido popularmente como Proyecto Bafuloto ${ }^{39}$ se proponía desarrollar la infraestructura básica (en particular la carretera y aeroportuaria) para el desarrollo del turismo. Se designó un área de alrededor de $750 \mathrm{~m}$ de ancho y $15 \mathrm{~km}$ de largo al oeste de Banjul (la capital), a lo largo de la costa, especialmente dedicada al turismo: el Área de Desarrollo Turístico. Allí se fue desarrollando la infraestructura y oferta de servicios y se construyeron muchos hoteles - en gran medida a través de inversión extranjera directa- que atrajeron a un número creciente de turistas.

El número de llegadas internacionales a Gambia se multiplicó en más de cinco veces entre 1972-1973 y 1993-1994, y pasó de 15584 a 89997 . En esta tendencia creciente en la afluencia de turistas se perciben, sin embargo, los efectos negativos de los problemas políticos internos mencionados párrafos arriba. ${ }^{40}$ Así, el intento de golpe de Estado de 1981 se tradujo en una caída notable en las llegadas internacionales, que bajaron de 19209 en 1980-1981 a 13331 en 1981-1982. La percepción de que se había tratado de un suceso pasajero ocasionó que el crecimiento se restaurara a partir de 1982-1983. Más adelante, el golpe de Estado de 1994 tuvo un efecto demoledor sobre la afluencia de turistas, debido a que los operadores turísticos británicos se retiraron casi por completo del país: ${ }^{41}$ si en 1993-1994 se registraron casi 90000 llegadas internacionales, éstas cayeron a menos de la mitad, cerca de 43000 , en la temporada 1994-1995; sin

${ }^{36}$ Peter U. Dieke, "Cross-national Comparison of Tourism Development: Lessons from Kenya and The Gambia”, Journal of Tourism Studies, vol. 4, núm. 1, 1993, pp. 2-18.

${ }^{37}$ Carlisle y Jones, “The Beach Enclave: A Landscape of Power”, op. cit.

${ }^{38}$ Dieke, "Cross-national Comparison...", op. cit.

${ }^{39} \mathrm{El}$ nombre se refería a una región alrededor de la playa que fue asignada al turismo (Carlisle y Jones, “The Beach Enclave: A Landscape of Power”, op. cit.).

${ }^{40}$ Richard Sharpley, "Tourism and Development Challenges in the Least Developed Countries: The Case of The Gambia”, Current Issues in Tourism, vol. 12, núm. 4, 2009, pp. 337-358.

${ }^{41}$ Idem. 
embargo, nuevamente el turismo se fue recuperando en los años siguientes, al restaurarse la estabilidad, y en 1998 ya había superado el nivel previo al golpe de Estado.

El papel de la inversión extranjera en la construcción de la oferta turística ha sido fundamental. Cabe notar que esta inversión ha tenido un origen muy diverso: Mitchell y Faal citan entre los principales hoteles algunos de propiedad sueca, británica, italiana e irlandesa; ${ }^{42}$ pero conviene subrayar que también aparecen otros propiedad de países no europeos: kuwaití, libia, mauriciana y libanesa; de hecho, la UNCTAD ${ }^{43}$ menciona a Gambia como un caso extremo de elevada participación de países no miembros de la Organización para la Cooperación y el Desarrollo Económicos como proveedores de inversión extranjera, cifrándola en 60 por ciento.

El crecimiento del turismo en Gambia mostraba, sin embargo, tres problemas importantes. El primero era que dependía de un pequeño número de mercados, sobre todo de Reino Unido y Escandinavia; ${ }^{44}$ el segundo, que era marcadamente estacional, ${ }^{45}$ con $80 \%$ de las llegadas en la temporada alta, de noviembre a abril, y, el tercero, que el efecto del turismo sobre el resto de la economía se percibía muy limitado, debido a que los turistas llegaban en paquetes prepagados, permanecían dentro del complejo hotelero y generaban muy escasas oportunidades para la población fuera de estos recintos.

Para solucionar este tercer problema, y bajo la presión tanto de los residentes locales como de las organizaciones no gubernamentales, ${ }^{46}$ en un episodio que ilustra la complejidad de las políticas públicas para aumentar el efecto del sector turístico sobre el resto de la economía, en 1999 el gobierno decidió prohibir los paquetes de vacaciones con todo incluido. El ministerio

${ }^{42}$ Jonathan Mitchell y Jojoh Faal, The Gambian Tourist Value Chain and Prospects for Pro-poor Tourism, informe inédito presentado a la Commonwealth Secretariat, 2006.

${ }^{43}$ United Nations Conference on Trade and Development, Foreign Direct Investment in LDCs: Lessons Learned from the Decade 2001-2010 and the Way Forward, Nueva York-Ginebra, UNCTAD, 2011.

${ }^{44}$ Sharpley, "Tourism and Development Challenges...”, op. cit.

${ }^{45}$ Jonathan Mitchell y Jojoh Faal, "Holiday Package Tourism and the Poor in The Gambia", Development Southern Africa, vol. 24, núm. 3, 2007, pp. 445-464; Sharpley, "Tourism and Development Challenges...", op. cit.

${ }^{46}$ Carlisle y Jones, "The Beach Enclave: A Landscape of Power”, op. cit. 
de turismo afirmó: “queremos que los visitantes interactúen con nuestro pueblo y cultura [...] si se restringe a los turistas a un lugar porque han pagado por adelantado las comidas y las bebidas, nuestro país no se beneficia. Los restaurantes y bares, taxis y vendedores de arte y artesanías locales sufren". ${ }^{47}$

Esta prohibición estuvo vigente un año, pero debido a la presión de los operadores turísticos, algunos de los cuales se retiraron por completo de Gambia, y a la caída en el número de turistas que esto ocasionó, la prohibición se eliminó en el año 2000. Esto no significó que se abandonara la idea de que debían tomarse medidas para aumentar la derrama económica del turismo hacia otros sectores, sino que se optó por una política pública distinta, consistente en promover la venta de productos y servicios locales a los turistas.

Mitchell y $\mathrm{Faal}^{48}$ presentan un análisis de los efectos del turismo sobre el resto de la economía de Gambia alrededor del año 2005 donde ponen atención especial en el efecto sobre la población pobre. Utilizan el método del "análisis de la cadena de valor" (value chain analysis), que identifica a los distintos participantes en el proceso de producción de los servicios turísticos y determina qué porcentaje del gasto de los turistas reciben estos participantes. ${ }^{49}$

Para entender la importancia de uno de los principales hallazgos de Mitchell y Faal, considérese primero que la gran mayoría de los turistas viajan a Gambia mediante paquetes prepagados. Sin embargo, los autores encuentran que considerar solamente los gastos correspondientes a estos paquetes es engañoso, pues la tercera parte del gasto total que realizan los turistas en sus vacaciones es gasto discrecional, no incluido en el paquete, realizado durante la estancia en Gambia, siendo las dos terceras partes restantes las destinadas al pago inicial del paquete. Esto es importante porque la magnitud de gasto discrecional eleva sustancialmente el efecto del gasto turístico sobre el

${ }^{47}$ Idem.

${ }^{48}$ Mitchell y Faal, "Holiday Package Tourism...”, op. cit.

${ }^{49}$ Más adelante menciono las estimaciones realizadas por el WTTC, Travel and Tourism Economic Impact, op. cit., de la contribución del turismo al PIB que incluyen -dentro de lo que llaman efecto indirecto del turismo- la inversión turística, como la construcción de nuevos hoteles, así como el producto que se genera inducido por el gasto de las personas empleadas directa o indirectamente en el turismo. 
resto de la economía y, particularmente, sobre los ingresos de la población pobre, por encima de lo que se obtendría si se considerara solamente el paquete prepagado.

Mitchell y Faal encuentran que cerca de la mitad del gasto total de los turistas - es decir, incluido también el gasto discrecional-se destina a los operadores turísticos internacionales y las líneas aéreas, y nunca llega a Gambia. La otra mitad del gasto es la que alimenta al sector turístico y hace de él una pieza clave en la economía. Encuentran que 14\% de este gasto llega directamente a la población pobre y que existen conexiones bien establecidas que permiten que la actividad turística beneficie a esta población; por ejemplo, en el caso de rubros menores de la cadena de valor, como las excursiones y las compras (como regalos y souvenirs), la mitad de las cuales se realizan en el sector informal.

Los dos rubros con más potencial de beneficio para aliviar la pobreza, sin embargo, son el empleo en los hoteles y la demanda de alimentos. Respecto al primero, Mitchell y Faal estiman que equivale a casi dos terceras partes de los empleos directos generados por el turismo. ${ }^{50} \mathrm{La}$ demanda de alimentos es al menos tan importante y tiene quizá más perspectivas de futuro por varias razones: primero, porque puede traducirse en demanda para la agricultura, a la que se dedica $70 \%$ de la población de Gambia; segundo, porque puede beneficiar a población que no necesita acudir a los centros turísticos, por lo que desde el punto de vista geográfico tiene un efecto más amplio que otros rubros que se concentran en la zona hotelera, una zona muy reducida -y la más rica-del territorio, y, tercero, porque el consumo de alimentos y bebidas (incluidos hoteles y restaurantes) es cuantitativamente muy elevado (representa 16\% del gasto total de los turistas, o $32 \%$ del gasto que realizan, excluida la parte pagada a líneas aéreas y operadores turísticos internacionales, que nunca llega a Gambia). ${ }^{51}$

Vale la pena subrayar que la provisión de alimentos aprovecha una característica distintiva del turismo: que lleva a los consumidores al país productor, y brinda a los productores

\footnotetext{
${ }^{50}$ Es decir, excluidos los empleos que son inducidos de manera indirecta por el sector turístico.

${ }^{51}$ Mitchell y Faal, "Holiday Package Tourism...”, op. cit.
} 
agrícolas de Gambia la posibilidad de vender sus productos sin necesidad de enviarlos fuera del país. Mitchell y Faal señalan que el sector agrícola efectivamente está aprovechando cada vez más este potencial. En 1986 sólo 35\% de los alimentos en los hoteles se surtía localmente (se importaba 65\%); veinte años después, encuentran que la provisión doméstica se había elevado entre $45 \%$ y $50 \%$; además, que hay una variación muy grande entre los hoteles: mientras que algunos surten hasta $90 \%$ de sus alimentos y bebidas localmente, otros los importan casi todos. Desde luego, esto indica que hay un margen importante para aumentar la provisión local de estos productos.

En otro estudio, Carlisle y Jones ${ }^{52}$ realizan una investigación con grupos de discusión formados por trabajadores que sin estar directamente empleados en los complejos hoteleros, tienen una relación especial con ellos para vender sus productos y servicios a los turistas, entre los que destacan los taxistas, vendedores de artesanías, guías de turistas y vendedores de jugos de frutas. Encuentran que estos grupos enfrentan dificultades para acceder a los turistas y promover sus productos y servicios. Esto se debe a que existe un circuito formado por los operadores turísticos internacionales y los complejos hoteleros, que trabajan en estrecha colaboración y crean un espacio al que es difícil acceder si no se garantiza que el turista esté adecuadamente protegido y seguro bajo ciertas condiciones de higiene y seguridad.

A la dificultad de acceso a los turistas deben agregarse otros obstáculos: los guías de turistas informales, a pesar de poseer una licencia, enfrentan el problema de carecer de un seguro adecuado, hecho que es usado para disuadir a los turistas de contratarlos, además de que la mayoría de los hoteles prefieren promover excursiones con operadores turísticos terrestres con los que tienen convenios. Los taxistas también enfrentan el problema del seguro, los vendedores de jugos de frutas encuentran dificultades para ser admitidos por razones de higiene y los vendedores de artesanías enfrentan en desventaja la promoción del hotel por sus propias artesanías.

A pesar de estas limitaciones, estos grupos logran vender sus productos y servicios a los turistas y, más aún, algunos tra-

${ }^{52}$ Carlisle y Jones, “The Beach Enclave: A Landscape of Power”, op. cit. 
bajadores informales han usado su experiencia y contactos para establecer negocios "menos estigmatizados". ${ }^{53}$

Los dos estudios anteriores nos proporcionan una idea de por qué es tan importante el turismo para la economía de Gambia. El wTTC estima ${ }^{54}$ que la contribución directa del turismo ${ }^{55} \mathrm{al}$ PIB de Gambia es de 8.2\%, y su contribución total, incluidos los efectos indirectos de las compras que realiza el sector turístico a otros sectores y la inversión turística, así como los efectos inducidos por el gasto de quienes están empleados directa o indirectamente en el sector turístico, asciende a $20.3 \%$ del PIB. ${ }^{56}$

La magnitud del efecto del turismo se debe no sólo al empleo directo en los hoteles, sino también a los trabajadores que como taxistas, guías de turistas, vendedores de artesanías y vendedores de jugos, por ejemplo, trabajan alrededor de los hoteles, además de las derramas adicionales a que aluden Mitchell y Faal, entre las que destacan las compras al sector de alimentos y bebidas, que tiene efectos sobre la agricultura y, finalmente, al gasto de todos estos sectores en el resto de la economía.

A pesar de la importancia cuantitativa de los efectos anteriores, en términos de su contribución al desarrollo económico de Gambia, el estado del sector turístico enfrenta problemas importantes e impone limitaciones innecesarias.

Una limitación importante es que se restringen las posibilidades de obtención de empleos mejor remunerados y de desarrollo del potencial de la población. En efecto, Mitchell y Faal ${ }^{57}$ encuentran que los puestos directivos de los hoteles están abru-

${ }^{53} \mathrm{Idem}$.

${ }^{54}$ WTTC, Travel and Tourism Economic Impact, op. cit.

${ }^{55}$ Que capta el gasto en turismo y viajes de residentes y no residentes, y corresponde al producto de sectores como hoteles, aerolíneas, aeropuertos, agentes de viaje y servicios recreativos que atienden directamente a los turistas.

${ }^{56}$ Datos para 2012. Como referencia, en 2011 la participación en el PIB del sector manufacturero rondaba $4.9 \%$, la del transporte $11.6 \%$, la de la agricultura, caza y pesca $32 \%$ y la de la construcción 3.6\%. (AFDB-OECD-UNDP-UNECA, African Economic Outlook, 2013). Nótese, sin embargo, que el cálculo del efecto del turismo, según el WTTC, no permite en rigor hacer comparaciones intersectoriales porque el turismo está medido de manera que incluye producción de diferentes sectores y conduciría a contar varias veces la misma actividad. Para una explicación detallada de este punto y, más generalmente, de las estadísticas del turismo, véase Dilys Roe et al., Tourism and the Poor: Analyzing and interpreting Tourism Statistics from a Poverty Perspective, Pro-poor Tourism working paper series, Londres, PPT Partnership, 2004.

${ }^{57}$ Mitchell y Faal, "Holiday Package Tourism...”, op. cit. 
madoramente ocupados por extranjeros, en una proporción igual a la que prevalecía veinte años antes; es decir, no se ha hecho ningún progreso al respecto. Mencionan que aunque la población no africana es sólo $0.7 \%$ del personal, recibe $15.5 \%$ de los sueldos y salarios. Con esta falta de movilidad de los trabajadores nativos se pierden adicionalmente muchos efectos inducidos, entre los que destacan la adquisición de habilidades que podrían trasladarse a otros sectores de la economía. Aquí hay, sin duda, lugar para la política pública en materia de educación y capacitación que podría contribuir al ascenso de la población nativa a empleos que requieren mayor cualificación y están mejor remunerados.

Otra limitación son las dificultades que enfrenta la población de Gambia para obtener financiamiento que le permita generar los productos o servicios que demanda el sector turístico, ya sea para la venta directa a los turistas, o indirecta mediante la integración en la cadena productiva. Esto se debe, en gran medida, a un sistema financiero poco desarrollado, que impide la entrada de nuevos participantes locales al mercado y hace que los participantes, ya presentes, tengan que autofinanciarse. Un hecho ilustrativo de la falta de acceso al capital lo proporcionan los casos de individuos que tienen que comprar hoteles al contado, en efectivo, opción que evidentemente está fuera del alcance de casi toda la población. ${ }^{58}$ Además de la política pública en materia financiera, también habría lugar para apoyar a los productores en las líneas mencionadas en la sección anterior.

En tercer lugar, aunque sí hay vínculos con el resto de la economía, hay un potencial para que estos vínculos se desarrollen mucho más; de hecho, las dos medidas anteriores contribuyen a aumentarlos, pero otra forma de crearlos y fortalecerlos está muy relacionada con la solución de otro problema que impide el crecimiento del sector turístico en sí mismo, no sólo de sus vínculos con el resto de la economía: la creación y mejoramiento de la infraestructura turística.

Los problemas de infraestructura se reflejan en multitud de aspectos, entre los que cabe destacar la infraestructura de transporte, limitada a la reducida zona en que se ubica el sector 
turístico, y el suministro de electricidad, que es caro y poco confiable, con frecuentes cortes que obligan a los hoteles a tener plantas propias. En el fondo, como argumenta Sharpley, esto obedece a que el gobierno "no alimenta a la vaca que ordeña", 59 es decir, que utiliza al sector turístico como una fuente de ingresos, a través de diferentes impuestos, pero no invierte lo suficiente en el desarrollo del sector.

El problema de la estacionalidad de la demanda, con una caída muy grande en el periodo de junio a noviembre, aunque no puede eliminarse totalmente, sí puede reducirse sensiblemente; de hecho, a lo largo de los años se ha venido reduciendo. ${ }^{60}$ Dos estrategias encaminadas en esta dirección son una mejor mercadotecnia y un mayor desarrollo de infraestructura. Uno de los mayores retos para lograrlo es que la temporada de junio a noviembre, más lluviosa y calurosa, es especialmente propicia para el desarrollo de la malaria -o paludismo-, lo que exige un sistema de prevención y monitoreo más amplio e intenso que en la temporada de noviembre a mayo.

Finalmente, en una perspectiva mucho más amplia, no deben ignorarse las experiencias de inestabilidad de 1981 y $1994 \mathrm{ni}$ el papel central que en última instancia tiene la estabilidad política en el desarrollo y sostenimiento del turismo. Un sistema político frágil se traduce en un sector turístico también frágil.

\section{Cabo Verde}

Situado en el Océano Atlántico a unos 600 kilómetros de Senegal, Cabo Verde es un archipiélago compuesto por diez islas - de las cuales nueve están habitadas- con un área de poco más de 4000 kilómetros cuadrados. Estas islas suelen clasificarse en el grupo Barlovento, ${ }^{61}$ compuesto por Boavista, Sal, Santa Luzia (deshabitada), Santo Antão, São Nicolau y São Vicente, y el grupo Sotavento, compuesto por Maio, Santiago, Fogo y Brava. ${ }^{62}$

${ }^{59}$ Sharpley, “Tourism and Development Challenges...”, op. cit.

${ }^{60}$ Mitchell y Faal, "Holiday Package Tourism...", op. cit.

${ }^{61}$ Situadas en la parte de donde viene el viento, en oposición a las islas de Sotavento.

${ }^{62}$ Véanse Tomás López Guzmán, Osvaldo Borges y José María Cerezo López, 
Los portugueses tomaron posesión de las islas de Cabo Verde en el siglo Xv, cuando muy probablemente estaban deshabitadas, y las gobernaron hasta 1975, cuando Cabo Verde obtuvo su independencia. ${ }^{63}$

Las particulares circunstancias geográficas de Cabo Verde son importantes para entender su evolución tanto económica como social y política. En primer lugar, el hecho de ser unas islas que quedan de camino entre Europa y América las hace un punto conveniente de parada para los vuelos transatlánticos. El aeropuerto de la isla de Sal cumplió tal función, que incluso fue aprovechada por la Unión Soviética, Cuba y Sudáfrica en la década de 1980, debido a la política de no alineación del gobierno de Cabo Verde. ${ }^{64}$

En segundo lugar, las condiciones naturales de Cabo Verde la hacen extremadamente vulnerable. Carece de recursos naturales importantes y de condiciones favorables para el desarrollo agrícola; en particular, sufre la falta de lluvias que se transforma en sequías frecuentes. Históricamente, Cabo Verde ha sufrido estas sequías que han resultado en verdaderas hambrunas devastadoras; incluso en épocas tan recientes como la década de 1940, cerca de la cuarta parte de la población murió en dos hambrunas consecutivas. ${ }^{65}$ Estas condiciones generaron dos características centrales de la economía de Cabo Verde: por una parte, una gran cantidad de ayuda internacional y, por la otra, una oleada de emigración, que más adelante derivó en una gran cantidad de remesas.

\footnotetext{
"Community-based Tourism and Local Socio-economic Development: A Case Study in Cape Verde", African Journal of Business Management, vol. 5, núm. 5, 2011, pp. 1608-1617; Tomás López Guzmán, Osvaldo Borges y José María Cerezo López, "Una década de cambio económico en Cabo Verde: desde la emigración al turismo", Boletín Económico de ICE, núm. 3025, 2012, pp. 39-45, y Edson Redy Moreira Dos Santos y María Lorena Rodríguez Campo, "Destination Branding: A Reflective Analysis of Brand Cape Verde”, Place Branding and Public Diplomacy, vol. 10, núm. 1, 2014, pp. 87-102 (doi: $10.1057 / \mathrm{pb} .2013 .8$ ).

${ }^{63}$ David Atchoaréna, Patricia Dias Da Graça y José Manuel y Marquez, "Strategies for Post-primary Education in Small Island Developing States (SIDS): Lessons from Cape Verde”, Comparative Education, vol. 44, núm. 2, 2008, pp. 167-185.

${ }^{64}$ Peter Meyns, "Cape Verde: An African Exception”, Journal of Democracy, vol. 13, núm. 3, 2002, pp. 153-165.

${ }^{65}$ Jørgen Carling, "Emigration, Return and Development in Cape Verde: The Impact of Closing Borders", Population, Space and Place, vol. 10, 2004, pp. 113-132.
} 
Respecto al primer punto - como mencionan Atchoaeréna, Dias Da Graça y Marquez- ${ }^{66}$ la fragilidad de los Estados insulares pequeños (Small Island Development States) ha sido fuente de preocupación de diversos organismos internacionales, y en el caso de Cabo Verde su insularidad, lejanía y aislamiento geográfico, sumado a su precaria dotación de recursos naturales, incapacidad para producir los alimentos necesarios para la subsistencia de su población y su vulnerabilidad a desastres naturales y a variaciones en términos de intercambio justificaron una importante ayuda internacional. En los años siguientes a su independencia de Portugal, la Asistencia Oficial al Desarrollo fue la forma dominante de entradas de capital, y esta asistencia ha continuado, con variaciones de entre 30\% y $60 \%$ del PIB durante las últimas tres décadas. ${ }^{67}$

Respecto al segundo punto, tal como señala Carling, ${ }^{68}$ la historia de la emigración de Cabo Verde es un fenómeno de más de cien años de antigüedad, con sus altas y sus bajas. Esta emigración consiste en ir a trabajar fuera con la intención de volver a Cabo Verde y alcanzar un nivel de vida que no sería posible si se permanece en las islas. Está estrechamente relacionada con la idea de que las condiciones naturales del país son poco propicias para generar riqueza debido a la falta de recursos naturales y de condiciones favorables para el desarrollo agrícola. El otro lado de la moneda es la idea de que, si se cuenta con los medios económicos adecuados, Cabo Verde es un lugar ideal para disfrutar. Este tipo de migración entendida como un proceso de ir a trabajar fuera para volver y tener un mejor nivel de vida en Cabo Verde explica los grandes flujos financieros procedentes de las sucesivas oleadas de emigrantes a lo largo de la historia, que constituyen la diáspora, cuyo número se estima superior incluso a la población residente en Cabo Verde. ${ }^{69}$

El envío de remesas a familiares en Cabo Verde es una par-

${ }^{66}$ Atchoaréna, Dias Da Graça y Marquez, "Strategies for Post-primary Education...", op. cit.

${ }^{67}$ Yves Bourdet y Hans Falck, "Emigrants' Remittances and Dutch Disease in Cape Verde”, International Economic Journal, vol. 20, núm. 3, 2006, pp. 267-284.

${ }^{68}$ Carling, "Emigration, Return and Development...", op. cit.

${ }^{69}$ Bourdet y Falck, "Emigrants' Remittances and Dutch Disease in Cape Verde”, op. cit.; Carling, "Emigration, Return and Development...", op. cit. 
te inseparable del fenómeno migratorio. Adicionalmente, el regreso de los emigrantes está ligado a la entrada de más recursos financieros en diferentes modalidades, como las pensiones que reciben desde los países donde trabajaron y otro tipo de pagos a que se han hecho acreedores. La distribución de la diáspora es como sigue: 60\% en Estados Unidos, 25\% en Europa occidental y el resto en África, principalmente en Angola y Senegal. ${ }^{70}$ Las remesas provienen, en cambio, aproximadamente, $30 \%$ de Estados Unidos y $60 \%$ de Europa occidental. Bourdet y Falck señalan que el porcentaje de remesas proveniente de Estados Unidos es menor que el porcentaje de la diáspora en Estados Unidos porque la identificación y lealtad se reducen con el tiempo transcurrido desde la emigración, y la emigración a Europa es más reciente que a Estados Unidos. ${ }^{71}$

Entre 1985 y 2000 se observa una disminución de la ayuda internacional y un aumento de las remesas. Dos factores que han incidido en el aumento de las remesas son: i) el hecho de que, desde 1982, Cabo Verde ha sostenido un tipo de cambio fijo con el euro, y ii) la creación de cuentas de depósito especiales para las remesas de los emigrantes, con tasas de interés más elevadas que las de los residentes.

En 1995, las remesas eran ya la principal fuente de financiamiento externo de la economía caboverdiana. Comparadas con las otras principales fuentes de divisas extranjeras, la ayuda internacional, la inversión extranjera directa y el turismo, tenemos que del financiamiento provisto por estas cuatro fuentes, $46 \%$ provenía de las remesas, $38 \%$ de la ayuda internacional, 12\% de la inversión extranjera directa, y $4 \%$ del turismo. ${ }^{72}$

En avance de la exposición que presentaré más adelante sobre el desarrollo del turismo, cabe mencionar el cambio drástico op. cit.

${ }^{70}$ Bourdet y Falck, “Emigrants' Remittances and Dutch Disease in Cape Verde”,

${ }^{71}$ Por otra parte, dentro de Europa occidental, el origen de la remesas se concentra en Portugal, Holanda y Francia, que aportan cerca de la mitad del total de las remesas, a pesar de concentrar sólo $20 \%$ de la diáspora, aunque, de estos tres países, cabe destacar que Portugal aporta un porcentaje de remesas muy inferior al porcentaje de residentes, lo que se debe al menor ingreso per cápita en Portugal en comparación con Holanda y Francia (idem.).

${ }^{72}$ Los datos de la estructura de financiamiento externo provienen, tanto para 1995 como para 2007, de Márcio Valerio Ronci, Eduardo Carvalho De Castro y Amar Shanghavi, Cape Verde: Selected Issues, Washington, International Monetary Fund, 2008. 
de la estructura de financiamiento externo provista por estas cuatro fuentes de divisas extranjeras para 2007: 49\% provenía del turismo, $19 \%$ de las remesas, $18 \%$ de la inversión extranjera directa, y $14 \%$ de la ayuda internacional.

Un problema potencial de la entrada masiva de divisas por las cuantiosas remesas y ayuda internacional es que dañen la competitividad del sector exportador. Este fenómeno sería una manifestación de la llamada "enfermedad holandesa", ${ }^{73}$ que se produciría al aumentar la demanda de bienes para la población residente en detrimento del sector exportador. Bourdet y Falck realizaron un ejercicio econométrico para analizar este fenómeno en Cabo Verde y encontraron que efectivamente se presenta pero que su magnitud es reducida. Consideran que esto se debe a que no sólo los montos de remesas y ayuda son importantes, sino también la forma que toman y el uso que se les da. ${ }^{74}$

En Cabo Verde, tanto las remesas como la ayuda han tomado cada vez más un carácter que permite incrementar la capacidad productiva del país, en lugar de dedicarlas fundamentalmente al consumo de la población residente; es decir, la ayuda se orienta cada vez más claramente a fines productivos, para mejorar la infraestructura del país y la educación y salud de la población, y las remesas, además de eso, a inversiones que aprovechan la creación de esta infraestructura. Adicionalmente, la introducción de medidas como la reducción temporal de impuestos a las ganancias de las empresas exportadoras y facilidades para la importación de insumos intermedios también ha contribuido a promover la competitividad del sector exportador.

Como expliqué líneas arriba, la estabilidad política y la paz social son una condición indispensable para el desarrollo del sector turístico. En el caso de Cabo Verde, la formación y consolidación de un gobierno democrático que ha garantizado estas condiciones lo han distinguido como un caso sobresaliente en África subsahariana. Más aún, la "gobernanza" ha sido, según algunos autores, la característica más distintiva de Cabo Verde.

${ }^{73}$ Véase Christine Ebrahim-Zadeh, "Dutch Disease: Too Much Wealth managed Unwisely”, Finance and Development, vol. 40, núm. 1, 2003, pp. 50-51.

${ }^{74}$ Bourdet y Falck, "Emigrants' Remittances and Dutch Disease in Cape Verde”, op. cit. 
Con unos índices de corrupción baja, ha generado un marco institucional que ha evitado las situaciones extremas, que en otras partes han hecho imposible que la ayuda internacional rinda frutos.

Cuando Cabo Verde obtuvo su independencia, lo hizo en estrecha relación con Guinea-Bissau. En las dos colonias portuguesas un mismo movimiento de liberación, el Partido por la Independencia de Guinea y Cabo Verde (PAIGC), había guiado el proceso de liberación anticolonial. Su fundador, Amílcar Cabral, nació en Guinea-Bissau de padres caboverdianos. Y al lograr su independencia, el PAIGC obtuvo el poder en ambos países. Esta estrecha relación y las similitudes entre ambos países parecían augurar un futuro similar, pero no fue así.

En 1980 hubo un golpe de Estado en Guinea-Bissau que llevó a la fracción caboverdiana del PAIGC a formar un nuevo partido, del Partido por la Independencia de Cabo Verde (PaICV), que así rompió el movimiento que con un mismo partido actuaba en los dos países. Como argumenta Meyns, un factor importante en la explicación de por qué en Cabo Verde se evitó el camino golpista de Guinea-Bissau es que, en el proceso para lograr la independencia, mientras en el segundo país se desarrolló una guerrilla armada, en el primero no la hubo. ${ }^{75}$

El hecho de que en Cabo Verde no hubiera una militarización de la sociedad ni tampoco una lucha armada en su propio territorio contribuyó a una dinámica social y política distinta de la de Guinea-Bissau (y de otras colonias portuguesas, como Angola y Mozambique). En Cabo Verde se impuso una "lógica administrativa" en lugar de una "lógica de comando"; $;$ sin embargo, esto es sólo parte de la explicación. Las decisiones del grupo dirigente en el periodo posindependentista fueron importantes para escapar de la dinámica a que parecían conducir naturalmente los movimientos de liberación nacional triunfantes: al igual que otras ex colonias portuguesas en África, el PAIGC - y posteriormente el PAICV - obtuvo su legitimidad por su papel protagónico en la lucha por la independencia; además,

${ }^{75}$ Meyns, "Cape Verde: An African Exception”, op. cit.

${ }^{76}$ Fafali Koudawo, Cabo Verde e Guiné Bissaru: Da Democracia Revolucionária a Democracia Libera, Bissau, Instituto Nacional de Estudos e Pesquisa, 2001, citado por Meyns, "Cape Verde: An African Exception”, op. cit. 
tenía los medios para transformar este movimiento en un partido único, fenómeno que finalmente se produjo, después de una serie de disputas internas, en 1980, año en que se estableció una nueva Constitución que declaraba a Cabo Verde como un Estado con un único partido. ${ }^{77}$

A pesar de ello, diversos factores motivaron que el PAICV fuera capaz de abandonar el sistema unipartidista en favor del multipartidismo. Como argumenta Meyns, ${ }^{78}$ la caída de los regímenes socialistas de Europa del Este, a fines de la década de 1980, y la aparición de corrientes reformadoras a raíz de esta caída, suponían una transformación importante que los líderes del PAICV reconocieron rápidamente. Esta transformación hacía conveniente una apertura política y una mayor competencia democrática, especialmente en un país donde la ayuda externa -y, por tanto, las relaciones con los donantes extranjeros-desempeñaba un papel tan relevante. La dirigencia política estaba convencida de que la apertura era conveniente para el país, dadas las nuevas circunstancias internacionales, pero también confiaba en que podía ganar unas elecciones competidas. Había razones para suponerlo: el partido en el gobierno era el que había conducido a la independencia y, además, tenía un récord de mejoramiento de los niveles de vida y podía prometer la continuidad de este proceso en un marco de estabilidad.

En febrero de 1990, el PAICV se manifestó a favor del multipartidismo y, en enero de 1991, se celebraron las primeras elecciones parlamentarias competidas. La oposición, encarnada en el Movimiento por la Democracia (MPD), insistió en la larga permanencia del PAICV (15 años) en el poder, lo que consideraba autoritario y semejante a los regímenes socialistas de Europa del Este. El MPD obtuvo una victoria holgada en las elecciones, pues logró 56 de los 79 escaños en la Asamblea Nacional. El líder del MPD, Carlos Veiga, se convirtió en primer ministro y, un mes después, el también candidato del MPD, Arístides Pereira, ganó las elecciones presidenciales. Es importante subrayar que la transmisión de poder de un partido a otro se dio en un marco pacífico y que el PAICv aceptó la derrota.

${ }^{77}$ Meyns, “Cape Verde: An African Exception”, op. cit.

${ }^{78}$ Idem. 
El MPD, en contraste con el PAICV, siguió una línea liberal en el terreno económico, de reducción del papel del Estado en la economía. Su líder, Carlos Veiga, condujo a su partido a una nueva victoria en las elecciones parlamentarias de 1995 y, en este segundo periodo, aceleró las reformas favorables al sector privado; sin embargo, en 2001, en parte por divisiones internas, el MPD perdió el poder, al que retornó el PAICV. Esta segunda transmisión pacífica del poder de un partido a otro marcó la consolidación de la competencia democrática en Cabo Verde en un marco de estabilidad.

De acuerdo con Baker, ${ }^{79}$ en paralelo a la institucionalización de una democracia multipartidista, Cabo Verde fue desarrollando una administración pública competente, cada vez más sofisticada, que se convirtió en su principal activo para elevar el nivel de vida de sus ciudadanos. Esto se nota en una elevada calidad del gobierno en diferentes áreas; así, la corrupción en Cabo Verde es, de acuerdo con Transparencia Internacional, la menor en África sólo después de Botsuana y Mauricio. Baker subraya la importancia que tiene en este hecho el escrutinio público tanto de los medios de comunicación como, en menor medida, de la Asamblea Nacional; asimismo, la incorporación de las tecnologías de la información en la administración pública, en lo que se ha dado en llamar el "gobierno electrónico", ha reforzado la característica anterior y facilitado los trámites burocráticos a la población. ${ }^{80}$

La existencia de un sistema político democrático y una administración pública eficiente y honesta ha sido, de acuerdo con Baker, fundamental para tener una relación especial con la Unión Europea y conservar elevados flujos de ayuda internacional. ${ }^{81}$ No obstante, existen importantes aspectos que requieren atención en esta área; en particular, el mantenimiento de los re-

${ }^{79}$ Bruce Baker, "Cape Verde: Marketing Good Governance”, Africa Spectrum, vol. 44, núm. 2, 2009, pp. 135-147.

${ }^{80}$ Diferentes bases de datos gubernamentales se han hecho públicas en medios electrónicos, y la población puede realizar trámites, como la obtención de actas de nacimiento o el registro de vehículos, y obtener información y hacer preguntas sobre organismos gubernamentales por Internet (idem.).

${ }^{81} \mathrm{Idem}$. En esta misma referencia se citan varios casos que ejemplifican el papel del gobierno democrático y la intolerancia a la corrupción para obtener préstamos y atraer inversiones a Cabo Verde. 
cursos humanos en la administración pública, la igualdad de género (a pesar de la creación del Instituto Capoverdiano para Igualdade e Equidade de Genero) y la descentralización administrativa, relacionada con el hecho de la difícil movilidad entre las diferentes islas que se traduce en una deficiente atención desde la isla de Santiago, donde se encuentra Praia, la capital, a los problemas del resto de las islas.

La estabilidad política y la paz social, aunadas a un clima templado, ausencia de desastres naturales y una ubicación en el camino entre Europa y América, conveniente como parada para los vuelos transatlánticos, fueron ingredientes propicios para el desarrollo del turismo. Los inicios del turismo en Cabo Verde datan de la década de 1970, después de la construcción del aeropuerto internacional en la isla de Sal. Los vuelos que llegaban y partían diariamente proveyeron de un flujo de miembros de tripulación y algunos otros pasajeros que comenzaron a explorar la isla. En 1967, la familia belga Vyn Kier construyó la Pousada Morabeza, e inició así las actividades turísticas en Cabo Verde, en la isla de Sal. ${ }^{82}$

Sin embargo, el desarrollo del turismo como una actividad económica relevante en Cabo Verde es muy posterior; su crecimiento más importante se registra apenas a partir de fines del siglo pasado. En doce años, entre 2000 y 2012, el turismo creció a una tasa anual de $17.5 \%$; el número anual de visitantes se multiplicó casi cuatro veces, y pasó de 145076 en 2000 a 533877 en 2012, y el número de pernoctaciones casi se quintuplicó, de 684733 a 3.3 millones en ese mismo periodo. ${ }^{83}$

En suma, espoleado por la existencia del aeropuerto internacional nació y se desarrolló el turismo en la isla de Sal; después se extendió a las islas de Boavista, Santiago y São Vicente. En este desarrollo se siguieron dos modelos.

${ }^{82}$ Direcção Geral do Turismo, Plano Estratégico para o Desenvolvimento de Turismo em Cabo Verde 2010-2013, Praia, Ministério de Economia, Crescimento e Competitividade, 2010. Véase también Dos Santos y Rodríguez Campo, "Destination Branding...", op. cit.

${ }^{83}$ Los datos del año 2000 provienen de Direcção Geral do Turismo, Plano Estratégico..., op. cit., y los de 2012 del Instituto Nacional de Estatísticas de Cabo Verde, Estatísticas do Turismo 2012: Movimentaçao de Hospedes, Praia, 2013. Véase también Dos Santos y Rodríguez Campo, "Destination Branding...”, op. cit., para un panorama general. 
En las islas de Sal y Boavista se siguió un modelo de turismo de sol y playa en grandes complejos hoteleros extranjeros, convirtiéndose, con mucho, en las principales receptoras de la afluencia de turistas, pues recibieron, en 2012, 73.3\% de los visitantes al país (35.2\% en Sal y $38.1 \%$ en Boavista). ${ }^{84}$

En las islas de Santiago y São Vicente, en cambio, se desarrolló un turismo con empresas pequeñas manejadas por propietarios locales, que en 2012 recibieron $19.4 \%$ de los visitantes (12.9\% en Santiago y 6.5\% en São Vicente).

Las restantes islas sólo recibieron, conjuntamente, $7.2 \%$ de los visitantes. Un problema serio desde el punto de vista del efecto del turismo en el desarrollo del país es que estas islas restantes son precisamente las más pobres. Mientras que la incidencia de pobreza en las islas donde se concentra el turismo es de $13 \%$ en Sal, $15 \%$ en Boavista, $26 \%$ en São Vicente y $37 \%$ en Santiago, en el resto de las islas es mayor: $38 \%$ en Maio, $40 \%$ en São Nicolau, $42 \%$ en Fogo, $43 \%$ en Brava y $54 \%$ en Santo Antão. ${ }^{85}$ Adicionalmente, Sal y Boavista tienen una población muy reducida. El contraste entre Boavista y Santo Antão ilustra claramente el problema: Boavista, con sólo 4193 habitantes y una incidencia de pobreza de sólo $15 \%$, capta $38.1 \%$ de los turistas, mientras que Santo Antão, con una población diez veces superior, de 47124 , y una incidencia de pobreza de $54 \%$, casi no capta turistas. ${ }^{86}$

Respecto al origen de la inversión extranjera directa, destaca inicialmente la presencia italiana, con las cuantiosas inversiones que, en 1991, realizó el Grupo Stafannina. Este grupo, conjuntamente con inversionistas locales, fundó la compañía

${ }^{84}$ Los datos de distribución del turismo entre las islas provienen de Instituto Nacional de Estatísticas de Cabo Verde, Estatísticas do Turismo 2012..., op. cit. Véase también Dos Santos y Campo, "Destination Branding...”, op. cit. Nótese que Boavista ha superado ligeramente a Sal en recepción de turistas muy recientemente. En 2010, Sal recibió $40.4 \%$ de los turistas y Boavista, $38.1 \%$ (según cálculos realizados por el autor a partir de los datos proporcionados en López Guzmán, Borges y Cerezo, "Una década de cambio económico...", op. cit.).

${ }^{85}$ Jonathan Mitchell, Tourist Development in Cape Verde: The Policy Challenge of coping with Success, Londres, Overseas Development Institute, 2008. Datos referentes a 2004.

${ }^{86} \mathrm{Idem}$. Todos los datos de población e incidencia de pobreza provienen de esta fuente. 
Turim y construyó un complejo turístico en la isla de Sal. ${ }^{87}$ Posteriormente, se sumaron otros países, en especial Portugal y España, que, junto con Italia, en años recientes han provisto más de la mitad de la inversión extranjera directa que recibe Cabo Verde. ${ }^{88}$ El flujo de inversiones ha tenido un crecimiento muy elevado: en la primera década de este siglo la inversión extranjera directa se incrementó de cerca de 5\% del PIB a más de $11 \%$, concentrándose en el sector turístico, sobre todo en bienes raíces y construcción, pero incluyó también los sectores de energía, financiero y de telecomunicaciones. ${ }^{89}$

La relación entre el fenómeno migratorio expuesto líneas arriba y el sector turístico es notable en las islas de Santiago y São Vicente, donde los recursos financieros derivados de la migración, así como los conocimientos y habilidades para fundar $\mathrm{y}$ administrar pequeños desarrollos turísticos provinieron en gran medida de la diáspora: por ejemplo, en São Vicente cerca de la mitad de estas empresas fueron establecidas por migrantes que regresaron a Cabo Verde. ${ }^{90}$

Por su parte, López Guzmán, Borges y Cerezo López ${ }^{91}$ hacen un estudio de campo en la isla de Santiago, la más grande y poblada de Cabo Verde. Allí reside más de la mitad de la población y se encuentra la capital, Praia. Muy pocos hoteles son propiedad de cadenas extranjeras: la mayoría son pequeños establecimientos propiedad de caboverdianos. En la isla se encuentran Cidade Velha, el primer asentamiento europeo creado en la región, y el parque natural Serra Malagueta, que se suman a los atractivos de sol y playa para proporcionar a la isla una oferta turística más diversificada. En su estudio, corroboran el amplio uso que hacen los turistas - más de 75\% de los cuales proceden de Europa- de las pequeñas empresas, sobre todo de los restaurantes y servicios de alojamiento, y el alto grado de satisfacción por los servicios recibidos; encuentran que la mayoría de los tu-

\footnotetext{
${ }^{87}$ Direcção Geral do Turismo, Plano Estratégico..., op. cit. Véase también Dos Santos y Campo, Destination Branding...”, op. cit.

${ }^{88}$ Joan Loureiro, Manuel Martins y Ana Paula Ribeiro, Cape Verde: The Case for Euroization, FEP Working Paper 317, Porto, Universidade do Porto-Faculdade de Economia do Porto, 2009.

${ }^{89} \mathrm{Idem}$.

${ }^{90}$ Mitchell, Tourist Development..., op. cit.

${ }^{91}$ López Guzmán, Borges y Cerezo López, “Community-based Tourism...”, op. cit.
} 
ristas que hicieron uso de pequeñas empresas responden que sí volverían a recurrir a sus servicios. Su estudio confirma también que la abrumadora mayoría de los pequeños negocios son propiedad de caboverdianos y, además, que la mayoría de ellos tienen más de cinco años de antigüedad, lo que refleja la estabilidad del turismo en la isla y llama la atención sobre un activo importante: su experiencia acumulada.

El crecimiento acelerado del turismo en Cabo Verde en las últimas décadas lo ha llevado a convertirse en el principal motor del crecimiento económico. Representa $80.3 \%$ de las exportaciones del país, con una contribución directa al PIB de $15.3 \%$ y una contribución total, tomando en cuenta sus efectos indirectos e inducidos, de $44.1 \% .{ }^{92}$ Como señala Mitchell, ${ }^{93}$ es sorprendente el efecto tan elevado del sector turístico sobre el conjunto de la economía si se considera que Cabo Verde es una economía pequeña y muy poco diversificada, con una capacidad para proveer al sector turístico muy reducida; podría conjeturarse que debido a esto los lazos del sector turístico con el resto de la economía serían muy débiles y de ahí su muy reducido efecto, pero no es así: el sector turístico tiene un enorme peso sobre el conjunto de la economía. Dos factores son centrales para explicar este fenómeno.

En primer lugar, el hecho de que los salarios en el sector turístico de Cabo Verde son relativamente elevados y la inmensa mayoría de los trabajadores en este sector son caboverdianos; en segundo lugar, que el rápido crecimiento del sector turístico ha generado un crecimiento también muy elevado del sector de la construcción. La vinculación entre estos sectores explica, de acuerdo con Mitchell, la mitad del peso del sector turístico sobre el resto de la economía. En contraste, las compras de alimentos y bebidas, que suponen un componente muy im-

${ }^{92}$ Datos para 2012 provenientes de WTTC, Travel and Tourism Economic Impact 2013, op. cit. Como referencia, la participación en el PIB del sector manufacturero es de $6.2 \%$, la de la construcción de $12.4 \%$, la del transporte de $17.4 \%$, y la de la agricultura, caza y pesca de 9.2\% (AFDB-OECD-UNDP-UNECA, A frican Economic Outlook, 2013, datos de 2010). Reitero, sin embargo, la advertencia hecha líneas arriba de que el cálculo del efecto del turismo, según el WTTC, no permite en rigor hacer comparaciones intersectoriales porque el turismo está medido de manera que incluye la producción de diferentes sectores y conduciría a contar varias veces la misma actividad.

${ }^{93}$ Mitchell, Tourist Development..., op. cit. 
portante del gasto turístico y que tradicionalmente son una vía privilegiada para que el resto de la economía se relacione con el sector turístico y se abata la pobreza, en Cabo Verde no lo son. El sector turístico importa casi todos los alimentos y bebidas que requiere; pero esto ocurre simplemente porque Cabo Verde produce cantidades muy limitadas de alimentos, por lo que su importación no es algo particular del sector turístico, sino que refleja la situación general del país: Cabo Verde importa más de $80 \%$ de los alimentos que consume (aunque cerca de la cuarta parte de su población se dedique a la agricultura, sólo $10 \%$ de su territorio es cultivable). ${ }^{94}$

En suma, a pesar de ser una economía poco diversificada, con una limitada capacidad para proveer al sector turístico, éste tiene un muy elevado efecto sobre el conjunto de la economía; sin embargo, por la forma en que ese efecto se produce, la concentración geográfica es muy marcada, pues tanto la actividad turística consolidada como la construcción de nuevos desarrollos se concentran en las islas de Sal, Boavista, Santiago y São Vicente, sobre todo en las dos primeras.

En vista de lo anterior, una sugerencia natural de política pública es llevar a cabo acciones que vinculen al resto con las islas de Sal, Boavista, Santiago y São Vicente, para que la población de todas ellas pueda beneficiarse del crecimiento del sector turístico. Esta vinculación se refiere tanto a la posibilidad de que los turistas incluyan en sus viajes visitas a las islas que ahora están marginadas del sector, como al crecimiento del comercio entre las islas. Mitchell sugiere algunas propuestas dirigidas a tener un servicio de transporte entre las islas, económico y de calidad (con vuelos locales y ferris), y un sistema de barcos y portuario que permita transportar y almacenar mercancías eficientemente. ${ }^{95}$

Respecto a la escasa vinculación del sector turístico con el agrícola, al que se dedica cerca de la cuarta parte de la población, el problema es que la producción de alimentos en Cabo Verde es muy reducida y, de hecho, el país no es autosuficiente en materia alimentaria. Como afirma Mitchell, para modificar esta

${ }^{94}$ Idem.

${ }^{95}$ Idem. 
situación deben atenderse problemas estructurales que tomará tiempo solucionar. ${ }^{96}$ Estos problemas residen fundamentalmente en el sector agrícola más que en el turístico. La estrategia de identificar insumos agrícolas específicos que necesite el sector turístico y que pudieran cultivarse en Cabo Verde es la que tiene mayor probabilidad de éxito.

\section{Reflexiones finales}

Concluyo este trabajo subrayando algunos elementos del significado del turismo en términos económicos en África subsahariana. Aunque en las décadas recientes el sector turístico ha crecido a tasas muy elevadas en el subcontinente, lo ha hecho de forma muy desigual, de manera que mientras que en muchos países se ha desarrollado, y en algunos se ha convertido en un sector importante de la economía, en otros es casi inexistente. Estos últimos casos se presentan con frecuencia por la falta de estabilidad política y paz social, condiciones indispensables para el desarrollo del turismo. La inestabilidad política y la ruptura de la paz social pueden tener efectos devastadores sobre el turismo, incluso en aquellos países donde se encuentra consolidado; por lo tanto, en muchas ocasiones las acciones más importantes para promover el turismo se encuentran fuera del ámbito estrictamente turístico, en el terreno de la construcción de instituciones y arreglos que garanticen la estabilidad.

Por otro lado, aunque el crecimiento del turismo puede ser un motor para el desarrollo económico, existe también el riesgo de que se trate de una actividad desligada de la economía local, dominada por intereses extranjeros, que beneficie fundamentalmente a los países de donde provienen los turistas y las inversiones, y ocasione más daños que beneficios a la población local.

En los casos de Gambia y Cabo Verde examinados, el sector turístico tiene un efecto muy elevado en el conjunto de la economía. La comparación de los dos países ilustra la diversidad de contextos, retos y posibles soluciones a que se enfrenta el desa-

${ }^{96}$ Idem. 
rrollo del sector turístico y su empleo como instrumento para el desarrollo en África subsahariana; en efecto, la forma en que el turismo se ha desarrollado, el contexto en que lo ha hecho y las condiciones que lo han propiciado muestran algunas similitudes en ambos países; pero también enormes diferencias. Entre las primeras destaca el hecho de que en ambos casos los sectores turísticos se iniciaron con inversión extranjera, que continúa teniendo un papel central; entre las segundas sobresalen el diferente grado de estabilidad política mostrado por ambos países - con episodios de ruptura de la paz social en Gambia- y la distinta forma de inserción en la economía mundial, donde resalta la enorme importancia de los flujos de ayuda internacional y de remesas procedentes de la migración en Cabo Verde, que con el tiempo ayudaron a financiar una parte importante del desarrollo del sector. La forma en que el sector turístico se relaciona con el resto de la economía también difiere; por ejemplo, mientras que en Gambia el sector agrícola suministra una parte cada vez más importante del consumo de alimentos en el sector turístico, esto no ocurre en Cabo Verde, que los importa en un enorme porcentaje.

Finalmente, ambos países enfrentan algunas dificultades comunes para que el crecimiento del turismo promueva el desarrollo económico. Una de ellas, central, es que el sector turístico se encuentra muy concentrado en las zonas más prósperas del país - en Gambia, en una reducida franja en la costa, y en Cabo Verde sobre todo en las islas de Sal y Boavista. Esto origina el problema de cómo extender los beneficios del turismo a otras zonas donde la incidencia de la pobreza es mucho mayor.

Un aspecto que no he analizado en el texto principal, pero que tiene relevancia para el desarrollo del turismo en África subsahariana, es la posibilidad de cooperación entre varios países de la región. Existe una gran variedad de políticas que pueden llevarse a cabo mediante esta cooperación y resultar en importantes beneficios para los países participantes.

La promoción de una región como un todo permite un mejor manejo de la mercadotecnia, mayor facilidad para "educar" a los intermediarios y superar percepciones negativas sobre África a un costo menor para los países participantes, que pueden compartir gastos y obtener economías de escala; asimismo, 
un grupo de países que actúa conjuntamente puede obtener mejores términos al negociar con las corporaciones turísticas transnacionales y facilitar a los turistas diversos trámites, entre los que sobresale el requisito de la visa. Por ejemplo, existe la propuesta de crear una visa única para la Comunidad de Desarrollo de África del Sur que facilitaría el turismo en la región. ${ }^{97}$

No menos importante: varios países que actúan conjuntamente pueden ofrecer un circuito turístico más amplio que cada país individual, y presentar así opciones más atractivas. Por ejemplo, Frost y Shanka ${ }^{98}$ proponen un acuerdo de cooperación entre Kenia y Etiopía, que agregaría a la oferta de playa y fauna del mercado consolidado de Kenia, una ruta histórica muy atractiva y una variedad más amplia de flora y fauna que proporcionaría el destino menos conocido de Etiopía. Permitiría la entrada de Etiopía al mercado turístico internacional con un riesgo bajo, constituyéndose en un destino que un segmento de turistas no considerarían de manera aislada pero sí como una extensión a la visita de Kenia. Para Kenia, un destino maduro, significaría extender su oferta turística, darle una dimensión adicional y obtener ahorros al compartir gastos en diferentes rubros.

Dirección institucional del autor:

Centro de Estudios Económicos

El Colegio de México

Camino al Ajusco 20

Pedregal de Santa Teresa

10740, México, D. F.

\jfernan@colmex.mx

\section{Bibliografía}

African Development Bank (AFDB)-Organization for Economic Cooperation and Development (OECD)-United Nations Development

${ }^{97} \mathrm{Un}$ análisis de las opiniones de los tour operadores sobre las consecuencias de esta propuesta puede encontrarse en Annely Douglas, Berendien Lubbe y Elizabeth Kruger, "Would a Single Regional Visa encourage Tourist Arrivals in Southern Africa?”, Development Southern Africa, vol. 29, núm. 3, 2012, pp. 488-505.

${ }^{98}$ Frederick Frost y Tekle Shanka, "Regionalism in Tourism: The Case for Kenya and Ethiopia”, Journal of Travel E Tourism Marketing, vol. 11, núm. 1, 2002, pp. 35-58. 
Programme (UNDP)-United Nations Economic Commission for Africa (UNECA), African Economic Outlook, 2013.

AкамA, John S., "The Evolution of Tourism in Kenya”, Journal of Sustainable Tourism, vol. 7, núm. 1, 1999, pp. 6-25.

AкAмA, John S., "The Role of Government in the Development of Tourism in Kenya", International Journal of Tourism Research, vol. 4, núm. 1, 2002, pp. 1-13.

Ashley, Caroline y Jonathan Mitchell, Can Tourism accelerate Propoor Growth in Africa?, Londres, Overseas Development Institute, 2005.

Ashley, Caroline, Charlotte Boyd y Harold Goodwin, "Pro-poor Tourism: Putting Poverty at the Heart of the Tourism Agenda", Natural Resources Perspectives, núm. 61, 2000, pp. 1-6.

Atchoaréna, David, Patricia Dias Da Graça y José Manuel Marquez, "Strategies for Post-primary Education in Small Island Developing States (SIDS): Lessons from Cape Verde", Comparative Education, vol. 44, núm. 2, 2008, pp. 167-185.

BA, Demba y Shaun Mann, Tourism: An Opportunity to Unleash Shared Growth in Africa, Africa Private Sector Development Note 16, Washington, World Bank, 2006.

BAKER, Bruce, "Cape Verde: Marketing Good Governance”, Africa Spectrum, vol. 44, núm. 2, 2009, pp. 135-147.

Bourdet, Yves y Hans Falck, "Emigrants' Remittances and Dutch Disease in Cape Verde", International Economic Journal, vol. 20, núm. 3, 2006, pp. 267-284.

Carling, Jørgen, "Emigration, Return and Development in Cape Verde: The Impact of Closing Borders", Population, Space and Place, vol. 10, 2004, pp. 113-132.

Carlisle, Sheena y Eleri Jones, "The Beach Enclave: A Landscape of Power", Tourism Management Perspectives, vol. 1, 2012, pp. 9-16.

De Sausmarez, Nicolette, "Challenges to Kenyan tourism since 2008: Crisis Management from the Kenyan Tour Operator Perspective", Current Issues in Tourism, vol. 16, núm. 7-8, 2013, pp. 792-809.

Dieke, Peter U., "Cross-national Comparison of Tourism Development: Lessons from Kenya and The Gambia”, Journal of Tourism Studies, vol. 4, núm. 1, 1993, pp. 2-18.

Direcção Geral do Turismo, Plano Estratégico para o Desenvolvimento de Turismo em Cabo Verde 2010-2013, Praia, Ministério de Economia, Crescimento e Competitividade, 2010.

Dos SAntos, Edson Redy Moreira y María Lorena Rodríguez Campo, "Destination Branding: A Reflective Analysis of Brand Cape 
Verde", Place Branding and Public Diplomacy, vol. 10, núm. 1, 2014, pp. 87-102.

Douglas, Annely, Berendien Lubbe y Elizabeth Kruger, "Would a Single Regional Visa encourage Tourist Arrivals in Southern Africa?", Development Southern Africa, vol. 29, núm. 3, 2012, pp. 488-505.

EBRAHIm-Zadeh, Christine, "Dutch Disease: Too Much Wealth managed Unwisely", Finance and Development, vol. 40, núm. 1, 2003, pp. 50-51.

Frost, Frederick y Tekle Shanka, "Regionalism in Tourism: The Case for Kenya and Ethiopia", Journal of Travel E Tourism Marketing, vol. 11, núm. 1, 2002, pp. 35-58.

Hoffman, Evan, "Towards Full Spectrum Conflict Prevention: The International Peace and Prosperity Project in Guinea-Bissau", Canadian Foreign Policy Journal, vol. 19, núm. 1, 2013, pp. 75-86.

Instituto Nacional de Estatísticas de Cabo Verde, Estatísticas do Turismo 2012: Movimentaçao de Hospedes, Praia, 2013.

López GuzMán, Tomás, Osvaldo Borges y José María Cerezo López, "Community-based Tourism and Local Socio-economic Development: A Case Study in Cape Verde", African Journal of Business Management, vol. 5, núm. 5, 2011, pp. 1608-1617.

López GuZmán, Tomás, Osvaldo Borges y José María Cerezo López, "Una década de cambio económico en Cabo Verde: desde la emigración al turismo", Boletín Económico de ICE, núm. 3025, 2012, pp. 39-45.

Loureiro, Joan, Manuel Martins y Ana Paula Ribeiro, Cape Verde: The Case for Euroization, FEP Working Paper 317, Porto, Universidade do Porto-Faculdade de Economia do Porto, 2009.

Meyns, Peter, "Cape Verde: An African Exception", Journal of Democracy, vol. 13, núm. 3, 2002, pp. 153-165.

Mitchell, Jonathan, Tourist Development in Cape Verde: The Policy Challenge of coping with Success, Londres, Overseas Development Institute, 2008.

Mrtchell, Jonathan y Jojoh Faal, "Holiday Package Tourism and the Poor in The Gambia", Development Southern Africa, vol. 24, núm. 3, 2007, pp. 445-464.

MrtChell, Jonathan y Jojoh Faal, The Gambian Tourist Value Chain and Prospects for Pro-poor Tourism, informe inédito presentado a la Commonwealth Secretariat, 2006. [odi.org.uk/sites/odi. org.uk/files/odi-assets/publications-opinion-files/3802.pdf, consultado el 29 de enero de 2014.]

Nobelli, Marina, Nigel Morgan y Carmen Nibigira, "Tourism in a 
Post-Conflict Situation of Fragility", Annals of Tourism Research, vol. 39, núm. 3, 2012, pp. 1446-1469.

Perfect, David, "Politics and Society in The Gambia since Independence", History Compass, vol. 6, núm. 2, 2008, pp. 426-438.

RoE, Dilys et al., Tourism and The Poor: Analyzing and interpreting Tourism Statistics from a Poverty Perspective, Pro-poor Tourism working paper series, Londres, РPT Partnership, 2004.

Rogerson, Christian M., "Reviewing Africa in the Global Tourism Economy", Development Southern Africa, vol. 24, núm. 3, 2007, pp. 361-379.

Ronci, Márcio Valerio, Eduardo Carvalho De Castro y Amar Shanghavi, Cape Verde: Selected Issues, Washington, International Monetary Fund, 2008.

SAINE, Abdoulaye, "Post-Coup Politics in Gambia", Journal of Democracy, vol. 13, núm. 4, 2002, pp. 167-172.

Sallah, Tijan M., "Economics and Politics in The Gambia", The Journal of the Modern African Studies, vol. 28, núm. 4, 1990, pp. 621648.

Sharpley, Richard, "Tourism and Development Challenges in the Least Developed Countries: The Case of The Gambia”, Current Issues in Tourism, vol. 12, núm. 4, 2009, pp. 337-358.

SINCLAIR, Thea, "Tourism and Economic Development: A Survey", The Journal of Development Studies, vol. 34, núm. 5, 1998, pp. 151.

United Nations Conference on Trade and Development, Foreign Direct Investment in LDCs: Lessons Learned from the Decade 20012010 and the Way Forward, Nueva York-Ginebra, UNCTAD, 2011.

United Nations World Tourism Organization, Tourism Highlights. 2013 Edition, Madrid, 2013.

United Nations World Tourism Organization, Tourism Market Trend. 2006 Edition, Madrid, 2006.

World Travel and Tourism Council, Travel and Tourism Economic Impact 2013, Londres, 2013. 
